\title{
關於齿输、机床和机械製造工藝方面 研究工作远景計劃的菁見
}

\author{
雷 天 覚 \\ （第一机俄工業部第一設計分局）
}

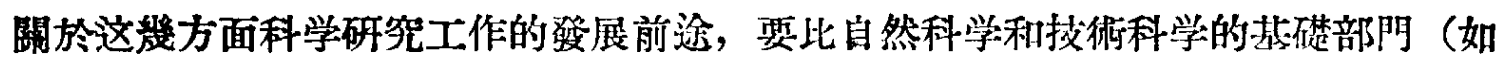
工程力学）难於預見。因为它一方面要受到基礎科学發展的影响，另一方面又必須比较

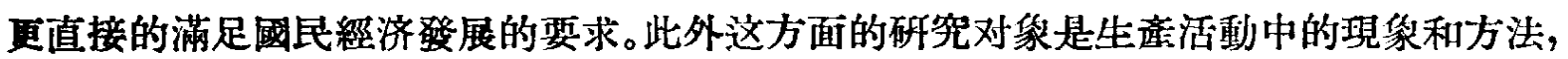

莫重點自不能不隨着生方方法的改進而有所变邆。这样，这幾方面研究工作的發展对其 他事物的發展便有着較大的依賴性。因此在远景計劃中，只能拈議範闪和方问，具体題 目僅能靚为举例。

在这方面的工作，从定远景語劃的角庭看，似乎可以分为四个類型：(1) 可对國家 工業建設在某些方西的决策上發生影响的關鍵研究工作。(2)一般推進科学技街设展的 究工作。（3）对國內創造和發現的科学總結、整理和更深入一步的研究。(4) 㙂。 性的研究工作:。

一、可能对工業建設在某些方面的决策上没生影响的研究工作。这一類型的工作,

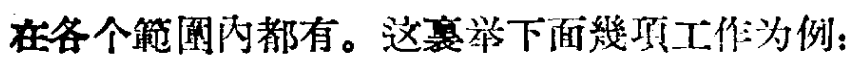

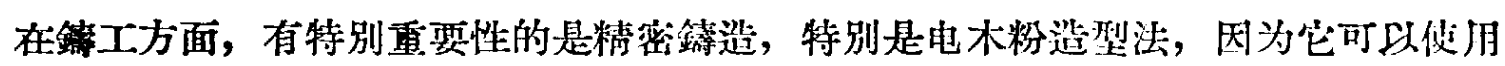

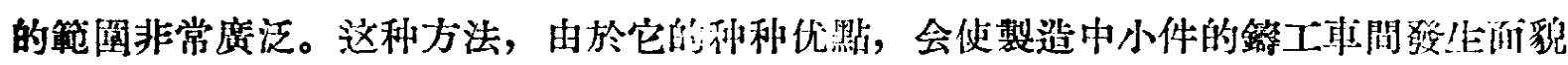
上的改变。同時由於鋳作加工餘量的減小，也会使金工車間的大小和組成發生一定的变

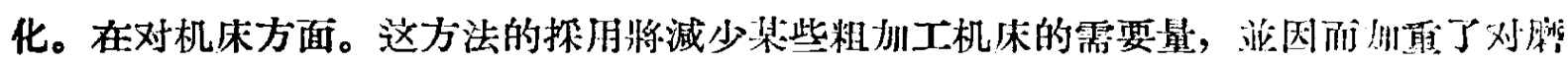
本的要求。因此, 这項工作的成果便会影响到國家机械工桨建設的長远针劃和以後的新 般設壾方法。

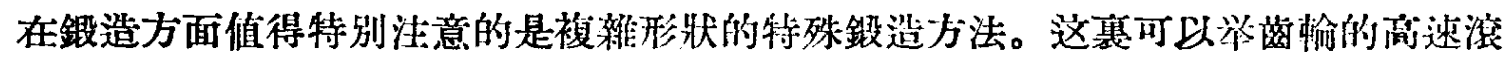
野为例。这方法的成功虽然远在 1911 作, 但因为在工業上的使用受到阻碍, 因此资料很

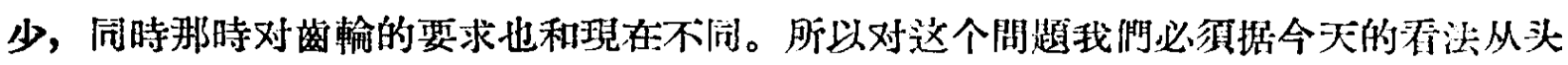

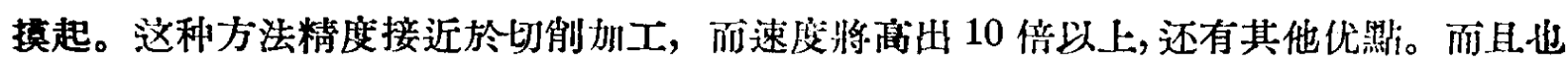
还可希望将这方法推席到其他形狀的鏙件。因此这一項研究工作的成就，就会使落輸製 造和鍛工技術發生一定的变化。

在机械加工方面似乎应当注意电加工（电火花、电弧、电解）和化学加工这一方伯 的研究。这方面到目前还必須認为亚不成熟。發展的速度和可能發展的限度都还难誰。 但侗能發展, 則我們有可能將电能直接加於工作物而取消机㦿和刀具兩个环節, 便不但 
簡化了机床, 还有可能提高加工速度。因此电加工方法如能發展, 則可能要排挤一部分 的切削加工。所以对电加工不但要推淮它的發展，还必須經常估計它在一定將來時期內 可能發展的限度。否則整个机床的發展路線要帶宣目性。

在加工方面另一个重大問題就是各种研磨方法的研究。目前中小件加工餘量的減小, 已有了不少途徑。因此將承便有可能将更多零件不經过切削加工而直接在磨床上完成全

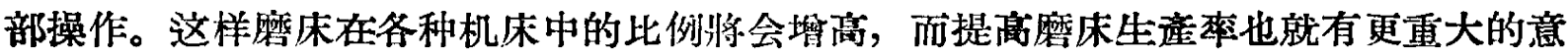
义。这方面需要的研究工作很多，如提高咱位能量所能去除的切属重量，研究更有效的

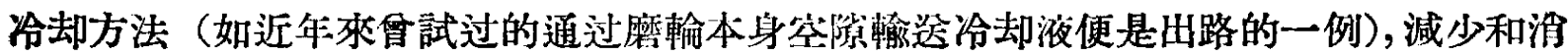
除某些磨床工作的装夾工時和装夾的自動化等等。

在机床設計方面以下幾个問題是帶共闰性和全面性的: (1) 液压在傳動和控制及輔 助操作上的应用。（2）彷型設备, 特別是液压、气压和光电管的彷型設备。以上兩方面 对机床操作的自動化有很大的影响。(3) 軸承和潤滑。(4) 導軌的魔擦和磨損。由於 近年來机床速度猛進的提高，(3)、(4) 兩方面有很多必須解决的問題, 如大型立式車 床的轉速已受到導軌軸承磨損的限制。也有不少解决問題的線掌。如在軸承方面，用油

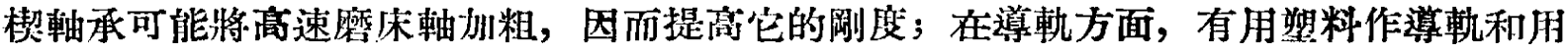
流動性贺料滲入金屬孔隙等方法。（5)机休在加工过程中的自動計量。这點也是到自動 化涂徑中必須解决的一个問題。这虽是一个很早的成就，但仍有新開展，必須進行研究 (如利用油膜進行砂輸在使用中磨耗的訫量)。以上这些研究工作都会对机床工業的發展 起一定的决定作用。

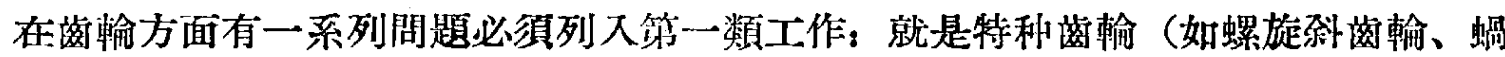
輸、錐蛣輸）的研究工作。这些东唒虽然都证不新，但过去因为資本蒙嘎断的關係，公 開的資料釷不多。然而这些都是最先進的技術，我們必須掌握。因此必須抓緊研究。在 苏联發展的歴文中，这些技術是学握得比较暗的。在我們因为工業發展得更晚，对这問 題的研究似乎更应該提早一步。例如对螺旋科齔輸的製造和製造設备等問題如果不及時 解决，对汽車工業便会起障碍作用。

以上是对第一个類型工作举了一些重點的例。这類工作似乎应放在最优先地位，而 且应該放在研究工作訫劃的早期。在力量非常有限的時候，这些問題的研究也可能要佔 去力量的一大部分。

二、一般推進技德的研究工作。这類工作因为是一般性的, 举个別的例会掛一漏万, 現以金屬切㓱和机床和刀具的震動兩項研究为典型。这類研究工作在过去已發展到很活 程度，而我們地可以从文件上得到很多資料。这類工作选題方法，似乎是应将國外已作 过的工作最近的一段重複一下，如果發現新的線索，便再可一點深入。个人意見，認为 在我們力量有限的時候不应單純追求艰樑的問題，而应比較强解研究工作發生的效果。

（这點可能和自然科学的研究有些不同）以防止为研究而研究的超势, 而使工作趋於繁 珼。例如在金屬切削的研究中，䂰究切展上应力分佈是一个比較艰深的問題，效果可能

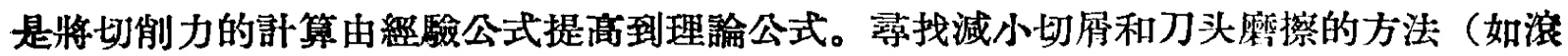
動刀头的研究）則是比较粗粘的工作，效果却可將切削速度大大提高。就这問題諭，在 我們力量还不足的時候, 似乎应該將力量集中在後者。事实上倘溒動刀头的应用能推 
度，則一般刀头上切㓱应力分佈这問題的重要性也就減小了。）

三、对國內創造和發現的整理總結和更深入的研究。我國科学虽然落後, 但在生 活動却仍会不断的有㓱造和發現。倘这些創造和發現索涉到一个較大的面或未䌊仔湅究 研过的原理，則应該用科学方法來整理研究，否則难望珜固和推痿。这方面可举一事实 瞈明: 在三年前某工激因压直熱处理到棺硬度的工件很困难, 便想到利用達朗貝尔原理

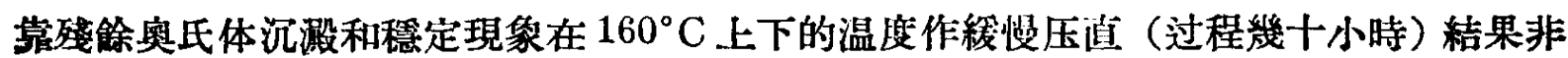
常有效。但当時限於力量, 没有作進一步研究, 說明这推理是否正確, 也沒有時間細查 一下交件，看这方法过去是否有人研究过。因而用过之後便不了了之的放下了。像这類 問題似乎可以提交研究机關來作一个系統的研究。因为这方法如果科学的整理出來，肯 定是有很多用处的。像这類工作，自然很难事先定計劃，但似可逐年調查搜集，在每一 年度內留出一定百分數的工作量來進行。

四、探索性的研究。在書籍交献中我們常会看到一些值得注意的研究情报，但是很 孤立，事後没有繼續作工作。又我們在工作和接觸中，也会想到一些間題，不能肯定也

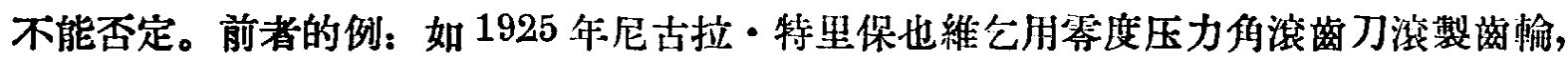
在大至 0.22 时的淮給下得到滿意的光樑度。又如 1921 年 A.L. 德勒歐夫朋一种旋轉刀

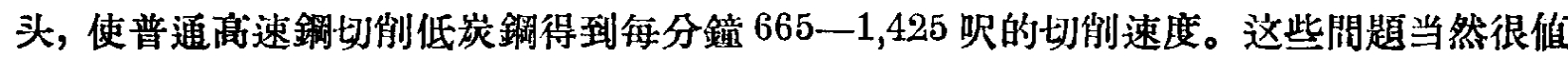
得注意, 但以後都没有具体使用过。

像这一類的線索，如果留意搜集，是会經常發靦的。而且由这种線索發覚的題目， 經研究得到很大的成就，在科学这上也不乏前例。因此我个人意見对这些線索应选出其 中有現实意义的部分，作一些探索性的研究（簡單的試驗、初步的理論分析等)。經探索 性研究而肯定了的閂題，再列入正式研究計劃。这当然也只能逐年留出一定的工作书， 無法一次穴排。

以上四个類型的工作其中第一類因为对工業建設的影响比较重大，而且都是比较長 期的工作，似乎应該在远景計劃中作比較具体的安排。第二類則不宜規定得太死，而是 悢常的根据研究工作的情報选題。但选題的原則必須有桝確的規定，因为在我們这力: 很有限的時候繁犋的研究太多是不大適宜的。第三、第四雨類則可作为閉拓新工作筙国 的手段。只規定每年的工作量，而不列具体計劃。

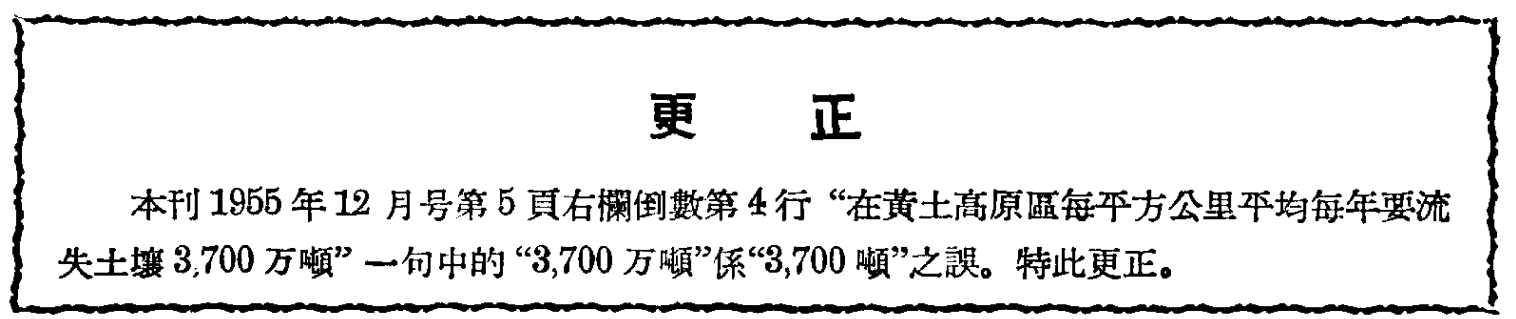

